\title{
Intra-ocular Lens Master V4 versus LenStar LS900 in Intra- ocular Lens Power Calculation and Postoperative Refraction Prediction
}

\author{
Sara A Sallam, Moataz A Sallam*, Mohamed E Shahin, and \\ Tarek M Radwan
}

Ophthalmology Department, Faculty of Medicine, Suez Canal University Hospitals, Egypt

\begin{abstract}
Background: The non-contact optical methods are preferable in Intra-ocular Lens (IOL) power calculation as they have higher resolution, better patient tolerance and greater acceptability. Aim: to compare between LENSTAR LS900 and IOL Master V4 in IOL power calculation. Material and Methods: This prospective comparative study included 60 eyes of 40 cataract patients. Patients with immature cataract of any age and both genders were included while those with dense cataract, media opacities, previous ocular diseases or surgeries or intraoperative complications were excluded. Patients were assessed by a complete comprehensive ophthalmic evaluation. Each patient was evaluated twice, one by the IOL Master and the other by the LENSTAR LS900. Outcome measures were axial length (AL), vertical keratometric dioptric power (K1), horizontal keratometric dioptric power (K2), and IOL power measurements. Results: The mean age of the patients was $67.08 \pm 5.34$ years. Thirty-five patients were males and 25 were females. The IOL master and LENSTAR were similar ( $p>0.05)$ in terms of the AL ( $24.82 \pm 2.21$ and $24.80 \pm 2.20)$, K1 (43.13 \pm 1.66 and $43.14 \pm 1.68)$, $K_{2}(44.14 \pm 1.56$ and $44.27 \pm 1.52)$ and IOL power $(16.86 \pm 5.24$ and $16.84 \pm 5.26)$. The target refraction on IOL master was $-0.01 \pm 0.06$ compared with $0.04 \pm 0.10$ on LenStar. The actual refraction was $0.00 \pm 0.33$. There were non-significant differences between target and actual refractions on both devices ( $p>0.05$ ). Conclusion: Both the optical biometers, IOL Master and LENSTAR provide similarly precise biometry and IOL power calculation in cataract patients.
\end{abstract}

Keywords: Optical biometry; IOL power calculation; Target refraction

\section{Introduction}

Accurate calculation of IOL power is mandatory to get a precise postoperative refraction $^{(1)}$. Ultrasound biometry has been used as the gold standard in IOL calculation for many years. Unfortunately, this contact method has some disadvantages; the results of this method are variable due to the indentation of the cornea during the measurements and also depend on the exact axial replacement of the probe relative to the center of the cornea(2). Additional drawbacks are the discomfort of the patients from the eye probe contact in applanation biometry, increasing the incidence of corneal abrasions or infections and the unstable operator-dependent performance $(3,4)$. The non-contact optical methods are more preferable as they have

*Corresponding Author: moataz.sallam@med.suez.edu.eg 
significantly higher resolution, better patient tolerance and greater acceptability ${ }^{(5)}$. Thus, they are preferred for biometry of the eye ${ }^{(6)}$. The partial coherence interferometry $(\mathrm{PCl})$ is supposed to be the most frequently used biometry device in clinical practice. It demonstrates precision and reliability in both cataract biometric assessment and in the evaluation of myopic characteristics. The IOL master measures the axial length $(\mathrm{AL})$ by $\mathrm{PCl}$ and offers an assessment of the keratometric $(K)$ readings, horizontal iris length and anterior chamber depth (ACD) by image analysis(5). Each assessment requires instrumental realignment with the visual axis of the eye. However, no AL measurement could be performed in eyes with advanced cataract ${ }^{(7-9)}$. Novel ocular biometry developed by Haag Streit (Lenstar; LS900) has become a useful non-contact instrument for biometry ${ }^{(10)}$. It can provide accurate data about central corneal thickness (CCT), ACD, retinal thickness (RT), lens thickness (LT) and axial length $(A L)$ by optical low coherence reflectometry (OLCR). Without the need for realignment, Lenstar can assess keratometry and pupil diameter through image analysis simultaneously within each measurement ${ }^{(10-12)}$. Therefore, this study aimed to compare the accuracy of these two noncontact methods in IOL power calculation in cataract patients.

\section{Materials and Methods}

The study was approved by the ethical committee of the Faculty of Medicine, Suez Canal University under the research acceptance number: 2622 . This study was conducted as a prospective comparative study (diagnostic study; level III evidence) comparing outcomes of Lenstar LS900 and IOL Master $V_{4}$ for calculation of IOL power and prediction of postoperative refraction for 60 eyes of 40 cataract patients who attended the outpatient clinic of the Ophthalmology Department; Suez Canal University Hospitals. An ethical approval was obtained from our institutional research board and research ethics committee in accordance with the tenets of the Declaration of Helsinki before commencement of the study. Informed consent was obtained from all participants. Patients older than 60 years of both sexes with immature cataract according to the Lens Opacification Classification System III (LOCS III) ${ }^{(13)}$ were enrolled in the study. While patients with histories of associated ocular disease such as uveitis, glaucoma, corneal opacity and keratoconus, previous ocular surgeries or high risk of intraoperative complications were excluded from the study. At baseline, all participants had full history taking and complete ophthalmic examination, including visual acuity assessment using Landolt C chart and decimal notation, slit-lamp biomicroscopy (Topcon, DC-3, Japan) for anterior and posterior segment, Goldmann applanation tonometry (GAT). Each eye was assessed using both devices [Lenstar (LS 900 Optical Biometer from Haag-Streit USA, Inc) and IOL master (V4, Carl Zeiss Meditec AG, Germany)]. The same trained investigator (S.S.) performed all keratometric readings, $A L$ measurement and IOL power calculation. Both devices were calibrated according to manufacturer recommendations prior to undertaking the measurements.

\section{Measurement technique}

Patients were positioned with a headrest and asked to fixate on an internal target within each device. They were instructed to perform a complete blink immediately before each measurement. The IOL power was calculated using Holladay 1 formula was used for eyes with axial length between $22 \mathrm{~mm}$ and $26 \mathrm{~mm}$ and SRK-T formula was used for eyes with axial length more 
than $26 \mathrm{~mm}$. For the IOL Master, the axial length measurement was based on a patented interference optical method known as partial coherence interferometry $(\mathrm{PCl})$. The corneal curvature was deter-mined by measuring the distance between reflected light images projected onto the cornea. The anterior chamber depth was determined as the distance between the optical sections of the crystalline lens and the cornea produced by lateral slit illumination. "White-to-white" was deter-mined from the image of the iris. The individual measurement procedures were automated so that the device was adjusted to the patient's eye and the measurement was initiated $^{(14)}$. For the LenStar LS900, the measurements taken are a central element of every IOL calculation. The IOL constant was used in calculating the lens to be implanted. The patient was positioned so that the distance from the measuring head to the eye is approx. $68 \mathrm{~mm}$. A steady head position was promoted by resting the patient's head in good contact with the chin rest and forehead band, and by the patient holding on to the handles supplied. The patient sat up as straight as possible. Then, the patient stared at the red fixation light in the measuring lens during measurement. So, the optical path length of the visual axis was measured. The keratometry was calculated through the position of 32 projected light reflections. Two rings, with sixteen measuring points on each eye, were arranged in two rings with outer diameter measuring points: $2.3 \mathrm{~mm}$ and inner measuring points: $1.65 \mathrm{~mm}$. For each measuring point, the equivalent of an ideal sphere is calculated ${ }^{(15)}$.

Surgical technique and postoperative care Patients underwent uneventful phacoemulsification using the same platform (AMO Sovereign), the same technique (stop and chop) and the same intra-ocular lens implanted (AcrySof, SA60AT, Alco
Inc., USA) with A-constant 118.4. the operations were done under local peribulbar anesthesia. Postoperative refraction using Nidek autorefractometer and visual acuity using Landolt broken ring (C) chart and decimal notation, were assessed 3 months after surgery. All patients received the same postoperative treatment which included broad spectrum antibiotic drops such as (Vigamox, Alcon, USA), steroid drops (Pred Forte, Allergen, Ireland) and antibiotic/steroid combination ointment (Tobradex, Alcon, USA) for two weeks.

\section{Assessment of outcomes}

Outcomes measures included axial length measurements, vertical keratometry, horizontal keratometry and IOL power, visual acuity and postoperative refraction.

\section{Statistical Analysis}

Statistical analysis was done using SPSS 20 (Statistical package for social science) and Microsoft Word 2010. Data were presented in tables and graphs. Patients' demographics were presented as number of observation and percentages or mean and standard deviation. The association between the postoperative refraction and several possible variables, axial length, corneal curvature and equation used for IOL power calculation was checked by using the $\chi^{2}$ test for comparison of proportions and the t-test for comparison of means in 2 groups with $95 \%$ confidence level or $\mathrm{p}$ value $<0.05$. Correlation and differences of biometry measurements obtained with the two biometers was performed.

\section{Results}

Seventy-five cataract eyes were initially assessed. Fifteen of 75 eyes were excluded due to measurements failure as they had dense cataract, congenital cataract or poor fixation, or were of uncooperative 
patients. This left a total of 60 eyes (40 patients) available for analysis. Patients' demographic data were summarized in table 1. The mean age of the patients was 67.08 \pm 5.34 years ranged from $60-78$ years. Thirty-five patients (58.3\%) were males and $25(41.7 \%)$ were females. The operated eye was right in 35 patients (58.3\%) and left in 25 patients ( $41.7 \%)$. Our results reported no significant differences between IOL master and LenStar LS900 regarding the axial length, vertical keratometric reading, horizontal keratometric reading, IOL power, and the target refraction ( $p>.05$ ) (table 2 ).

\begin{tabular}{|l|c|}
\hline \multicolumn{2}{|l|}{ Table 1: Patients' demographic and clinical data } \\
\hline & Mean \pm SD \\
\hline Age, years & $67.08 \pm 5.34$ \\
\hline Male/Female & $17 / 23$ \\
\hline Right/Left operated eye & $35 / 25$ \\
\hline Average axial lengths eyes / High myopia eyes & $50 / 10$ \\
\hline Preoperative unaided distant visual acuity, decimal notation & $0.16 \pm 0.04$ \\
\hline Postoperative unaided distant visual acuity, decimal notation & $0.82 \pm 0.12$ \\
\hline
\end{tabular}

Highly significant positive correlations $(p<0.001)$ of the axial length $(A L)$, vertical keratometric dioptric power (K1), horizontal keratometric dioptric power (K2), and IOL power measurements existed between the IOL Master and LenStar. The val ues recorded from both devices were simi lar and close to the mean (figure 1a-d). The target refraction on $\mathrm{OOL}$ master was $0.01 \pm 0.06$ compared with $0.04 \pm 0.10$ on LenStar. The actual refraction was $0.00 \pm 0.33$. Target and actual refractions were similar on both devices ( $p>0.05$ ) (figure 2).

\begin{tabular}{|l|c|c|l|}
\hline Table 2: Comparison between biometric parameters on IOL master and LenStar \\
\hline & $\begin{array}{c}\text { IOL master } \\
(\text { Mean } \pm \text { SD) }\end{array}$ & $\begin{array}{c}\text { LenStar } \\
(\text { Mean } \pm \text { SD) }\end{array}$ & P value* \\
\hline Axial length, mm & $24.82 \pm 2.21$ & $24.80 \pm 2.20$ & 0.063 \\
\hline Vertical keratometric reading (K1), D & $43.13 \pm 1.66$ & $43.14 \pm 1.68$ & 0.898 \\
\hline Horizontal keratometric reading (K2), D & $44.14 \pm 1.56$ & $44.27 \pm 1.52$ & 0.124 \\
\hline IOL power, D & $16.86 \pm 5.24$ & $16.84 \pm 5.26$ & 0.083 \\
\hline Target refraction, D & $0.02 \pm 0.061$ & $0.04 \pm 0.097$ & 0.062 \\
\hline
\end{tabular}

* Paired $t$ test

\section{Discussion}

We achieved similar outcomes for both IOL master and LENSTAR in measuring accurate biometric parameters. The cataract density was assessed in our patients using the lens opacification classification system III (LOCS III) ${ }^{(13)}$ as it is the worldwide accepted classification system for grading and management of cataract. We depended on an automated assessment of the refraction. Three readings of autorefractometer were taken and then average of these was taken as final reading. This allowed fast assessment of the refraction through non-dilated pupils. 


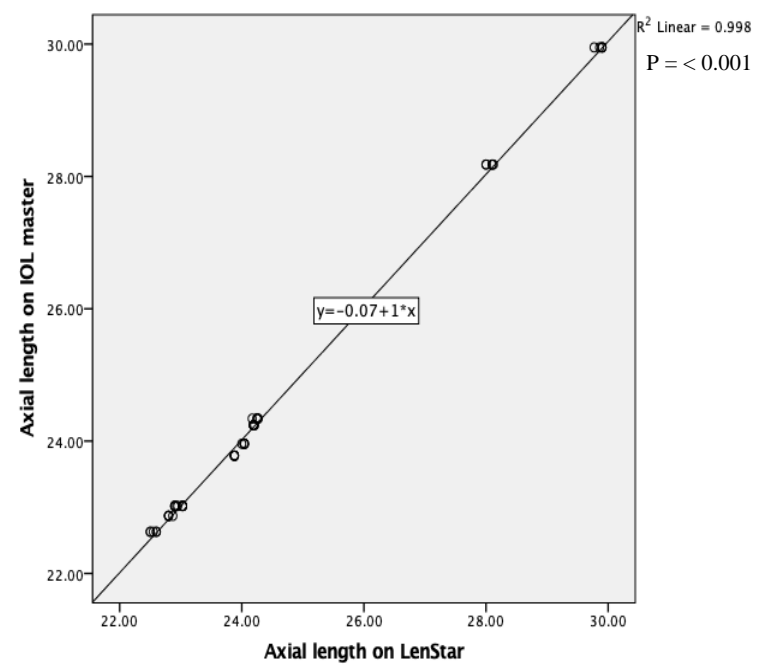

(A)

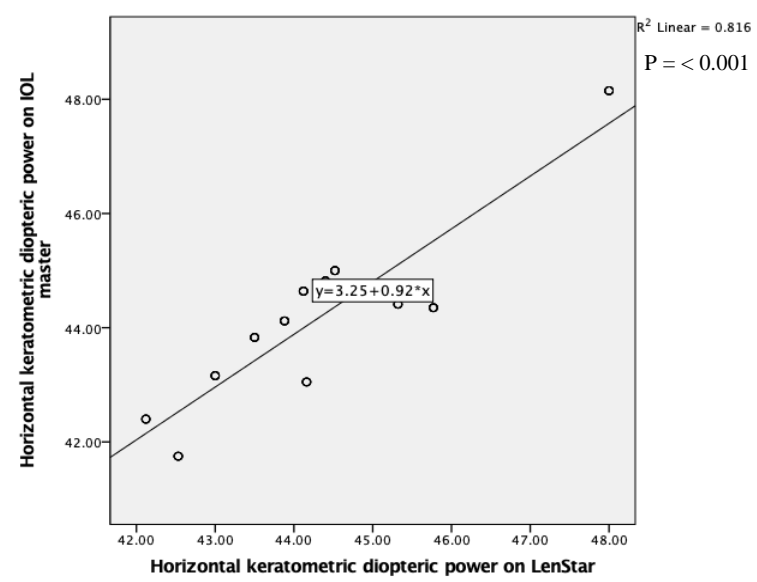

(C)

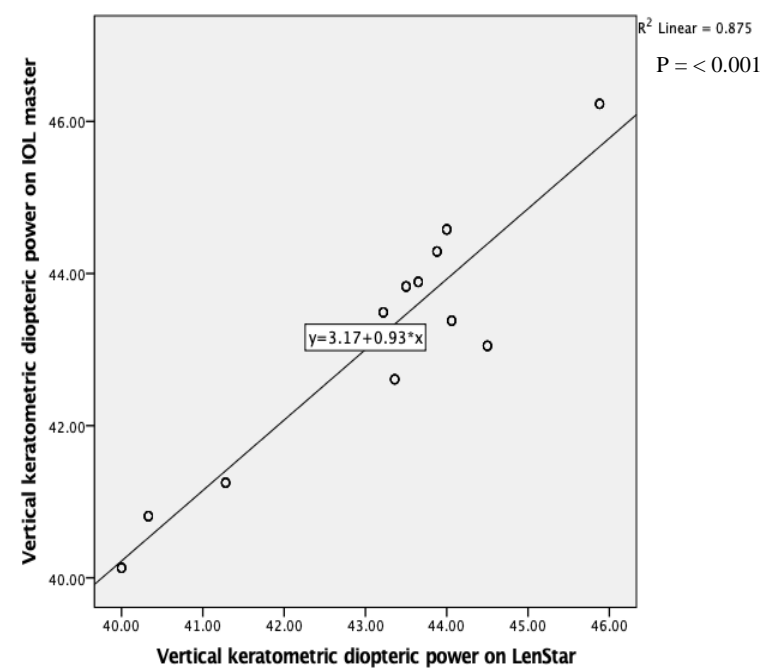

(B)

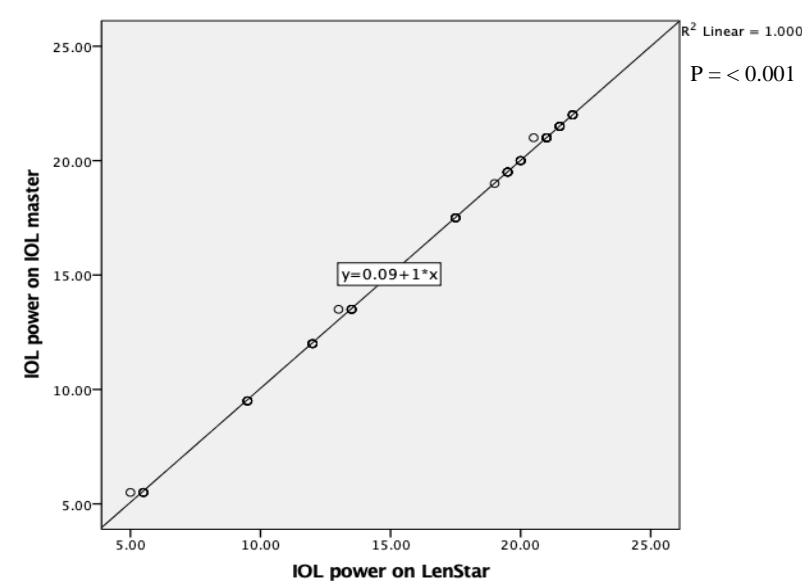

(D)

Figure 1: Correlation between IOL master and LenStar regarding biometric parameters; (a) axial length, (b) vertical keratometery, (c) horizontal keratometry and (d) IOL power

As patients were old, no effect of the accommodation affected the refraction results. In our study, there was neither statistically nor clinically significant difference between the mean axial length on IOL master which was longer and on LENSTAR which was shorter. These results were consistent with other studies that have found that the AL measurements with IOL Master were longer than those with the LENSTAR LS 900, but the difference was likewise deemed not clinically significant ${ }^{(16-18)}$. In contrast, Alvaro Ortiz et al. ${ }^{(19)}$ reported statistically significant differences in the measurement of the AL between the IOL Master 500, LENSTAR LS 900 and Aladdin with shorter axial length measurements taken by IOL master than that taken by the other two optical biometers. But the differences were within the range of only about $0.04 \mathrm{~mm}$. Regarding the IOL power calculation in our study, both the IOL master and LENSTAR reported similar outcomes. This, in turn, made no statistically significant differences in their postoperative target refractions. 


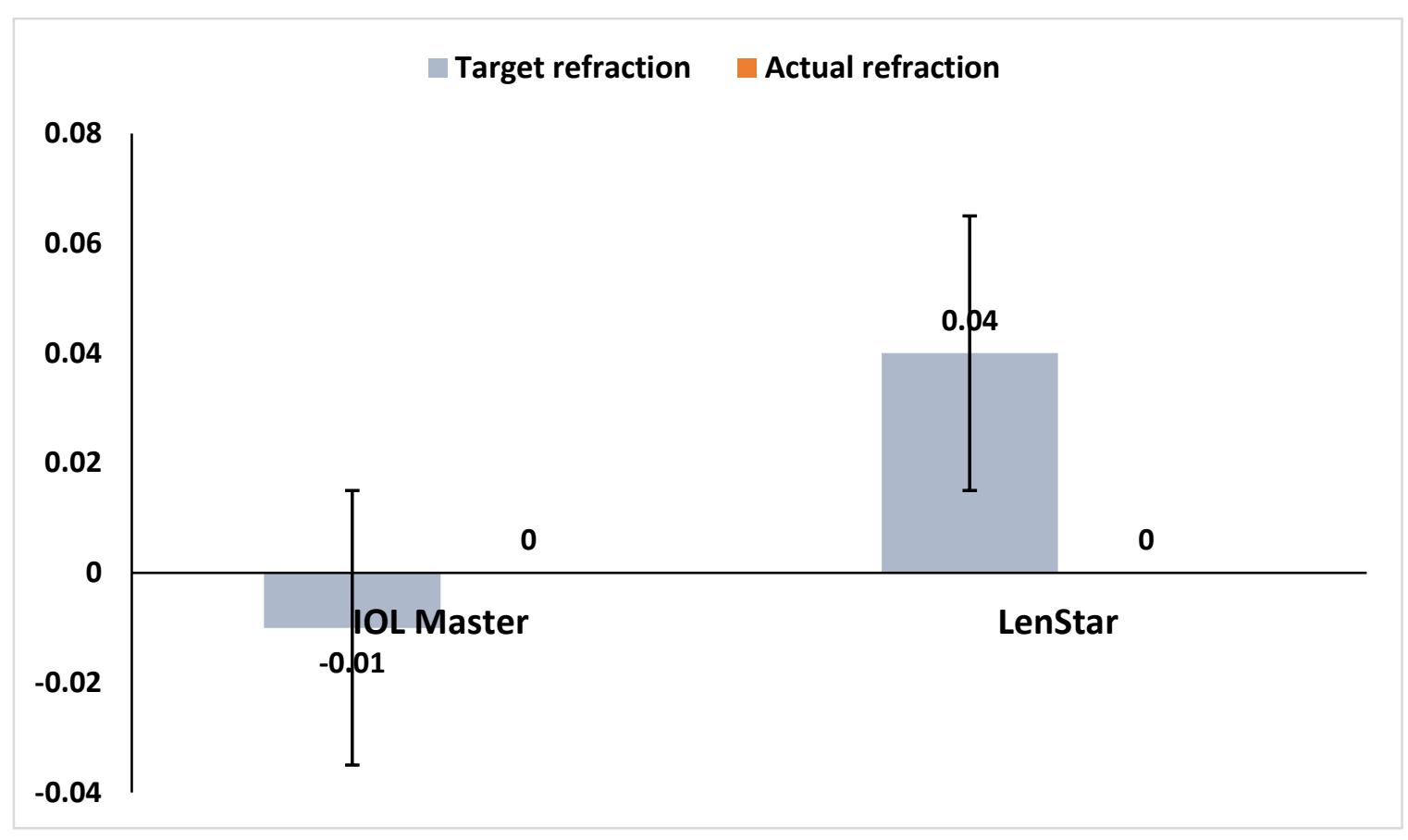

Figure 2: The target and postoperative actual refraction in both groups $(p>0.05)$. Whiskers represent standard error of the mean

These results are consistent with the results of Rabsilber et al. ${ }^{(22)}$ who evaluated 100 cataract eyes for IOL power calculations using IOL Master and LENSTAR. The mean difference in IOL power calculations using four formulas were similar between the two devices. A linear trend of the axial length $(A L)$, vertical keratometric dioptric power (K1), horizontal keratometric dioptric power (K2), and IOL power measurements between the IOL Master and LENSTAR existed. There were no differences between target and actual refractions on both devices. Our findings are in agreement with those of Rohrer K et al. ${ }^{(24)}$ who found well-correlations between measurements using both devices. A limitation of both devices is that they are incapable of providing an accurate measurement for all eyes, such as those with severe opacities along the visual axis, retinal detachment, and in case of poor patient cooperation ${ }^{(25)}$. As IOL master and LENSTAR are optical devices using laser light, any interference with the transmission of light can affect the results with these devices, especially the axial length measurement. Therefore, cataracts can interfere with measurements depending on the density and location. Buckhurst et al. ${ }^{(11)}$ found that the axial length measurement failed in 9 to $10 \%$ of the eyes. Mylonas et al. ${ }^{26)}$ reported that it was not possible to obtain axial length measurements with the IOL Master V.5 in $9.8 \%$ of the eyes and with the LENSTAR LS900 in $11.8 \%$ of the eyes. McAlinden et al. ${ }^{(27)}$ recorded a failure rate of $37.8 \%$ for the IOL Master (v5.4), and of $35.5 \%$ for the LENSTAR LS 900 while examining Chinese public hospital cataract patients. Our study has some limitations. Only senile cataract eyes were studied. The small sample size and lack of blinding were other limitations. However, our study was prospective in nature and comparisons between both devices were carried out. Moreover, to minimize the intra-rater bias in assessment of the refraction, the mean 
of three repeated measurements was used in our analysis. Another limitation of our study is that not up-to-date versions were used in investigating our patients. But these versions were the available resources in our institutions at the time of the study. Additionally, the newer versions do not differ from the used ones in our study in the assessment procedures and only included some recent equations and patients' conditions.

\section{Conclusion}

The optical partial coherence interferometry IOL Master and the low-coherence reflectometry LENSTAR devices provide a similarly precise biometry and a similarly accurate IOL power calculation in cataract patients. In practice, surgeons can depend on either device to get optimal results and surgery outcomes.

NB: The first and the second authors are equally contributed to the work.

\section{References}

1. Verhulst E, Vrijghem JC. Accuracy of intraocular lens power calculations using the Zeiss IOL master. A prospective study. Bull Soc Belge Ophtalmol. 2001;(281):61-5.

2. Marsich MW, Bullimore MA. The repeatability of corneal thickness measures. Cornea. 2000;19(6):792-5.

3. Miglior S, Albe E, Guareschi M, Mandelli G, Gomarasca S, Orzalesi N. Intraobserver and interobserver reproducibility in the evaluation of ultrasonic pachymetry measurements of central corneal thickness. $\mathrm{Br} J$ Ophthalmol. 2004 Feb;88(2):174-7.

4. Giers U, Epple C. Comparison of A-scan device accuracy. J Cataract Refract Surg. 1990 Mar;16(2):235-42.

5. Santodomingo-Rubido J, Mallen EAH, Gilmartin B, Wolffsohn JS. A new noncontact optical device for ocular biometry. $\mathrm{Br}$ J Ophthalmol. 2002 Apr;86(4):458-62.

6. Rainer $G$, Petternel $V$, Findl $O$, Schmetterer L, Skorpik C, Luksch A, et al. Comparison of ultrasound pachymetry and partial coherence interferometry in the measurement of central corneal thickness. J Cataract Refract Surg. 2002 Dec;28(12):2142-5.

7. Freeman G, Pesudovs K. The impact of cataract severity on measurement acquisition with the IOLMaster. Acta Ophthalmol Scand. 2005 Aug; 83 (4):439-42.

8. Suto C, Sato C, Shimamura E, Toshida H, Ichikawa K, Hori S. Influence of the signal-to-noise ratio on the accuracy of IOLMaster measurements. J Cataract Refract Surg. 2007 Dec;33(12):2062-6.

9. Hill W, Angeles R, Otani T. Evaluation of a new IOLMaster algorithm to measure axial length. J Cataract Refract Surg. 2008 Jun;34(6):920-4.

10. Cruysberg LPJ, Doors M, Verbakel F, Berendschot TTJM, De Brabander J, Nuijts RMMA. Evaluation of the Lenstar LS 900 non-contact biometer. $\mathrm{Br} \mathrm{J}$ Ophthalmol. 2010 Jan;94(1):106-10.

11. Buckhurst PJ, Wolffsohn JS, Shah S, Naroo SA, Davies LN, Berrow EJ. A new optical low coherence reflectometry device for ocular biometry in cataract patients. $\mathrm{Br} J$ Ophthalmol. 2009 Jul;93(7):949-53.

12. Holzer MP, Mamusa M, Auffarth GU. Accuracy of a new partial coherence interferometry analyser for biometric measurements. Br J Ophthalmol. 2009 Jun;93(6):807-10.

13. Chylack LTJ, Wolfe JK, Singer DM, Leske MC, Bullimore MA, Bailey IL, et al. The Lens Opacities Classification System III. The Longitudinal Study of Cataract Study Group. Arch Ophthalmol (Chicago, III 1960). 1993 Jun;111(6):8316.

14. Emerson J, Tompkins K. Preparing Your Patient for Testing, Taking Measurements and Lens Calculations. IOLMaster: A Practical Operation Guide [Internet]. Carl Zeiss Meditec, Inc. 2009. 
Available from: https://doctorhill.com/iol-power-calculations/opticalbiometry/

15. HAAG-STREIT Diagnostics. INSTRUCTIONS FOR USE: Biometer Lenstar LS 900 [Internet]. Haag-Streit AG, Switzerland. 2017. Available from: https://doctor-hill.com/iol-powercalculations/optical-biometry

16. Epitropoulos A. Axial length measurement acquisition rates of two optical biometers in cataractous eyes. Clin Ophthalmol. 2014;8:1369-76.

17. Stattin $M$, Zehetner $C$, Bechrakis NE, Speicher L. [Comparison of IOL-Master 500 vs. Lenstar LS900 concerning the calculation of target refraction: A retrospective analysis]. Ophthalmologe. 2015 May;112(5):444-50.

18. Goebels S, Pattmöller $M$, Eppig T, Cayless A, Seitz B, Langenbucher A. Comparison of 3 biometry devices in cataract patients. J Cataract Refract Surg. 2015 Nov;41(11):2387-93.

19. Ortiz A, Galvis V, Tello A, Viaña V, Corrales MI, Ochoa M, et al. Comparison of three optical biometers: IOL Master 500, Lenstar LS 900 and Aladdin. Int Ophthalmol. 2019 Aug;39(8):1809-18.

20. Shammas HJ, Ortiz S, Shammas MC, Kim $\mathrm{SH}$, Chong C. Biometry measurements using a new large-coherence-length swept-source optical coherence tomographer. J Cataract Refract Surg. 2016 Jan;42(1):50-61.

21. Hoffer KJ, Shammas HJ, Savini G. Comparison of 2 laser instruments for measuring axial length. J Cataract Refract Surg. 2010 Apr;36(4):644-8.

22. Rabsilber TM, Jepsen C, Auffarth GU, Holzer MP. Intraocular lens power calculation: clinical comparison of 2 optical biometry devices. J Cataract Refract Surg. 2010 Feb;36(2):230-4.

23. Hui S, Yi L. Comparison of two optical biometers in intraocular lens power calculation. Indian J Ophthalmol. 2014 Sep;62(9):931-4.

24. Rohrer K, Frueh BE, Wälti R, Clemetson IA, Tappeiner C, Goldblum D. Comparison and evaluation of ocular biometry using a new noncontact optical lowcoherence reflectometer. Ophthalmology. 2009 Nov;116(11):2087-92.

25. Lege BAM, Haigis W. Laser interference biometry versus ultrasound biometry in certain clinical conditions. Graefe's Arch Clin Exp Ophthalmol = Albr von Graefes Arch fur Klin und Exp Ophthalmol. 2004 Jan;242(1):8-12.

26. Mylonas G, Sacu S, Buehl W, Ritter M, Georgopoulos $M$, Schmidt-Erfurth $U$. Performance of three biometry devices in patients with different grades of agerelated cataract. Acta Ophthalmol. 2011 May;89(3):e237-41.

27. McAlinden C, Wang Q, Pesudovs K, Yang X, Bao F, Yu A, et al. Axial Length Measurement Failure Rates with the IOLMaster and Lenstar LS 900 in Eyes with Cataract. PLoS One. 2015; 10(6):e0128929. 